\title{
STUDY ON THE COUPLING RELATIONSHIP BETWEEN ECONOMIC SYSTEM AND WATER ENVIRONMENTAL SYSTEM IN BEIJING BASED ON STRUCTURAL EQUATION MODEL
}

\author{
CHEN, M. ${ }^{1,2^{*}}-$ CHEN, H. Q. ${ }^{3}$ \\ ${ }^{1}$ Ginling College, Nanjing Normal University, Nanjing 210024, China \\ ${ }^{2}$ Gulf Coast Research \& Education Center, University of Florida, Wimauma 33598, USA \\ ${ }^{3}$ School of Urban Planning, Yancheng Teachers University, Yancheng 224007, China \\ *Corresponding author \\ e-mail: Chenming.1008@163.com \\ (Received $20^{\text {th }}$ Sep 2018; accepted $26^{\text {th }}$ Nov 2018
}

\begin{abstract}
To study the relationship between the economic system and the water environmental system in Beijing, China, this article brought in the concept of "system coupling", and calculated their coupling degree using the co-coordination model. Specifically, the economic system consists of population and economic development subsystems; the water environmental system consists of water supply and water environmental carrying capacity subsystems. A total of twelve components were chosen, including population, water consumption per ten thousand Yuan GDP, etc. Besides, the Structural Equation Model (SEM) was innovatively used to analyze the micro-coupling paths among the subsystems. Finally, we drew conclusions from the coupling state perspective and coupling paths perspective, respectively. From the macroscopic point of view, there are complex interactions between the economic system and water environmental system in Beijing, and their coupling degree will increase with the optimization of economic structure and advancement in technologies. From the microscopic point of view, there are also complex interactions among the four subsystems in Beijing. Especially, the water supply subsystem has a certain degree of promotion effect on the other three subsystems.
\end{abstract}

Keywords: system coupling, micro-coupling paths, coordination degree analysis, structural equation model, pressure-state-response model

\section{Introduction}

The relationship between environment and economy has been a hot topic in academic circles for a long time (Corinne, 2014; Douai et al., 2012; Spach, 2011). As most researches focus on the environmental Kuznets curve and Eco-economic system, few types of research emphasize the concept of water environment (Van der Ploeg and Withagen, 2013; Aldy, 2005). In recent years, some scholars have researched into the relationship between the urban economic system and the water environmental system, and they concluded that the economic system and the water environmental system are the important components of the urban system (Flores et al., 2014; Ahmed et al., 2016; Apergis and Ozturk, 2015). On one hand, well-functioned economic system facilitates socioeconomic development, as well as brings about water pollution; on the other hand, water environmental system provides the water resources necessary for industry production and daily life. In addition, facing the pressure from water pollution, it is responsible for water purification and decontamination (Ben Jebli et al., 2016).

In this article, Beijing city is the research area as it is the largest city in the north of China. Based on the above-mentioned research results, the Beijing's urban system is composed of an economic system and a water environment system. To study the 
coupling degree between the economic system and the water environmental system, we first divided these systems into four subsystems, each of which consists of several sections The economic system consists of population and economic development subsystems. The population subsystem consists of gross population section, natural population growth rate section and urbanization rate section; the economic development subsystem consists of GDP section, water supply investment section and water consumption per ten thousand Yuan GDP section. The population subsystem provides the labor force capital necessary for the good function of economic development subsystem, which will in turn benefit the population subsystem. The water environmental system consists of water supply and water environmental carrying capacity subsystems. The water supply subsystem consists of the total amount of water supply for the whole year, water consumption for industry and water consumption for daily life; the water environmental carrying capacity subsystem consists of centralized processing rate of sewage, daily sewage treatment capacity and quantity of waste water effluent (Kanjilal and Ghosh, 2013; Chen and Xu, 2013). The water supply subsystem provides the water resources necessary for the functioning of the social economy, and the water environment carrying capacity subsystem absorbs the waste water and sewage caused by economic activities. In general, the economic system and water environmental system couple with each other and have complex interactions. Figure 1 is the economic \& water environmental system structure diagram of Beijing (Coscieme et al., 2016). This article aims to explore the complicated interplay between the economic system and the water environment system in Beijing, so as to find out practical and theoretical significance.

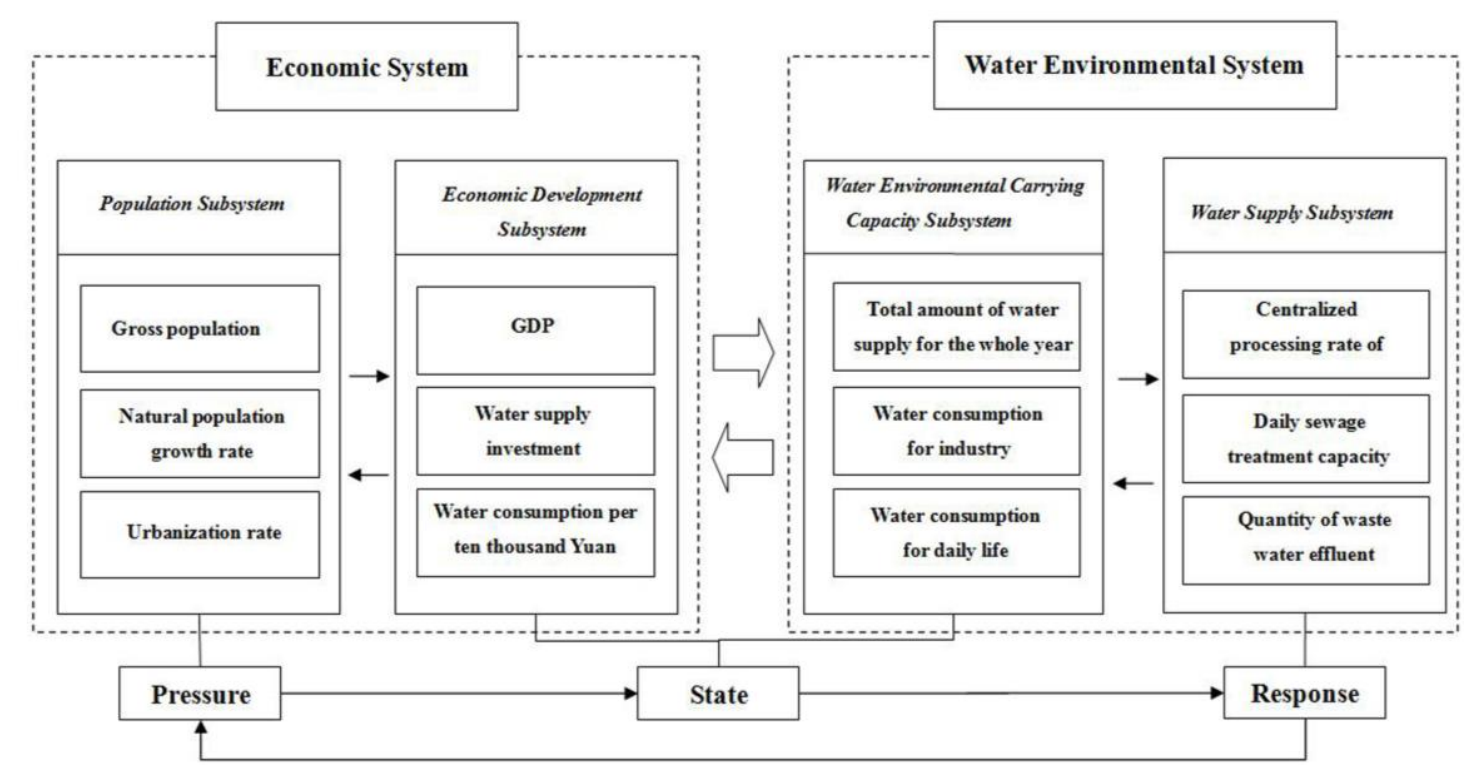

Figure 1. The economic \& water environmental system structure diagram of Beijing

\section{Material and methods}

\section{Data collection}

Beijing is the capital of China, and it is the largest city in the north of the country. Located in the north of the North China Plain (E 115.7 ${ }^{\circ}-117.4^{\circ}, \mathrm{N} 39.4^{\circ}-41.6^{\circ}$ ), 
Beijing has the jurisdiction over 16 counties, with a total area of $16410.54 \mathrm{~km}^{2}$ and the total population of 2170.5 million (2017). Affected by a typical temperate continental climate Beijing has an average annual precipitation of $585 \mathrm{~mm}$, and about $76 \%$ of the precipitation concentrated in the summer (June, July and August, 2017) (Fig. 2). The GDP of Beijing in 2015 is 229.66 billion Yuan (Lin et al., 2014). Compared with its developed economy, the water resources of this city are relatively scarce. The total water resources is 2.676 billion $\mathrm{m}^{3}$ (2015), per capita water resources is only $123 \mathrm{~m}^{3}$. Apparently, there is a certain contradiction between economic development and water resources supply (Xia et al., 2012).

The distribution of water system in Beijing is shown in Figure 2. It can be seen that 7 major river systems are in the Beijing area.

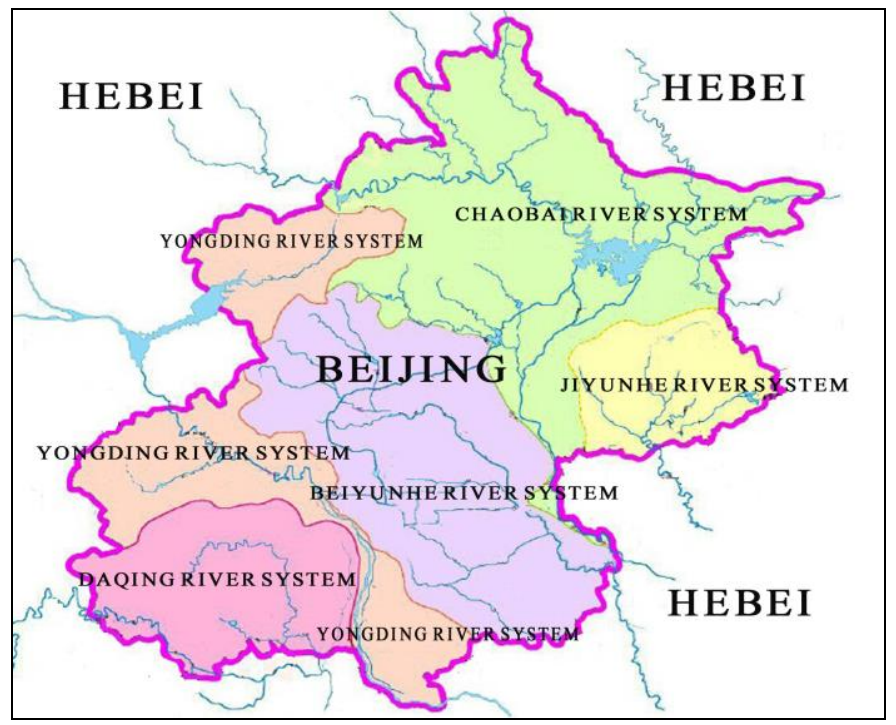

Figure 2. Distribution of water system in Beijing

In this article, all initial data were obtained from the Beijing Statistical Yearbook 1997-2013 and Beijing Water Resources Bullet 1997-2013. The total 12 components of economic system and water environmental system in Beijing are shown in Table 1.

Table 1. Components of economic system and water environmental system in Beijing

\begin{tabular}{|c|c|c|c|c|}
\hline System & Subsystem & Component & Symbol & Unit \\
\hline \multirow{2}{*}{$\begin{array}{l}\text { Economic } \\
\text { system }\end{array}$} & $\begin{array}{l}\text { Population } \\
\text { subsystem }\end{array}$ & $\begin{array}{l}\text { Gross population } \\
\text { Natural population growth rate } \\
\text { Urbanization rate }\end{array}$ & $\begin{array}{l}\mathrm{X}_{1} \\
\mathrm{X}_{2} \\
\mathrm{X}_{3}\end{array}$ & $\begin{array}{c}\text { Ten thousand people } \\
\% \\
\%\end{array}$ \\
\hline & $\begin{array}{l}\text { Economic } \\
\text { development } \\
\text { subsystem }\end{array}$ & $\begin{array}{c}\text { GDP } \\
\text { Water supply investment } \\
\text { Water consumption per ten thousand yuan } \\
\end{array}$ & $\begin{array}{l}\mathrm{X}_{4} \\
\mathrm{X}_{5} \\
\mathrm{X}_{6}\end{array}$ & $\begin{array}{c}100 \text { million yuan } \\
100 \text { million yuan/year } \\
\mathrm{m}^{3} \\
\end{array}$ \\
\hline \multirow{2}{*}{$\begin{array}{l}\text { Water } \\
\text { environmental } \\
\text { system }\end{array}$} & $\begin{array}{l}\text { Water supply } \\
\text { subsystem }\end{array}$ & $\begin{array}{c}\text { Total amount of water supply for the whole year } \\
\text { Water consumption for industry } \\
\text { Water consumption for daily life }\end{array}$ & $\begin{array}{l}\mathrm{Y}_{1} \\
\mathrm{Y}_{2} \\
\mathrm{Y}_{3}\end{array}$ & $\begin{array}{l}100 \text { million } \mathrm{m}^{3} / \text { year } \\
100 \text { million } \mathrm{m}^{3} / \text { year } \\
100 \text { million } \mathrm{m}^{3} / \text { year }\end{array}$ \\
\hline & $\begin{array}{l}\text { Water } \\
\text { environment } \\
\text { carrying capacity } \\
\text { subsystem }\end{array}$ & $\begin{array}{l}\text { Centralized processing rate of sewage } \\
\text { Daily sewage treatment capacity } \\
\text { Quantity of waste water effluent }\end{array}$ & $\begin{array}{l}\mathrm{Y}_{4} \\
\mathrm{Y}_{5} \\
\mathrm{Y}_{6}\end{array}$ & $\begin{array}{c}\% \\
10 \text { thousand } \mathrm{m}^{3} / \text { day } \\
10 \text { thousand } \mathrm{m}^{3} / \text { year }\end{array}$ \\
\hline
\end{tabular}




\section{Coupling coordination model}

Data pre-processing

Data were processed using the maximum difference normalization method. Evaluation indexes include: output index (Eq. 1), input index (Eq. 2).

$$
\begin{gathered}
X_{i j}^{\prime}=\frac{X_{i j}-\min \left(X_{j}\right)}{\max \left(X_{j}\right)-\min \left(X_{j}\right)} \\
X_{i j}^{\prime}=\frac{\max \left(X_{j}\right)-X_{i j}}{\max \left(X_{j}\right)-\min \left(X_{j}\right)}
\end{gathered}
$$

where $i=1,2, \ldots, N$ refers to years, $j=1,2, \ldots, N$ refers to parameters, $X_{i j}$ represents original values of the parameters, $X^{\prime}{ }_{i j}$ represents the value after standardization, $\max \left(X_{j}\right)$ and $\min \left(X_{j}\right)$ are the maximum value and minimum value of the parameter, respectively.

\section{Determining index weight using mean square deviation method}

The coefficient of variation $C V_{j}$ was introduced into the mean square deviation method to determine index weight. The calculation methods of $C V_{j}$ is shown in Equations 3 and 4 show calculation process of weighted value.

$$
\begin{gathered}
C V_{j}=\frac{\sigma_{j}}{\bar{X}_{j}} \\
W_{j}=\frac{C V_{j}}{\sum_{j=1}^{n} C V_{j}}
\end{gathered}
$$

where $C V_{j}$ represents the coefficient of variation, $\sigma_{j}$ represents the standard deviation of the $j$ th parameter, $\bar{X}_{j}$ and $W_{j}$ represent mean value and weighted value, respectively.

Calculating comprehensive index between economic system and water environmental system

The comprehensive indexes of economic system $f(x)$ and water environmental system $g(y)$ were obtained by multiplying the standardized value of parameters and their corresponding weights. The calculation methods of $f(x)$ and $g(y)$ are shown in Equations 5 and 6, respectively.

$$
\begin{aligned}
& f(x)=\sum_{i=1}^{m} X_{i j}^{\prime} W_{x} \\
& g(y)=\sum_{i=1}^{n} Y_{i j}^{\prime} W_{y}
\end{aligned}
$$

It should be noted that the standardized value of parameters $\left(X_{i j}^{\prime}, Y_{i j}^{\prime}\right)$ eliminate the influence of the units. Their corresponding weights $\left(\bar{X}_{j}, W_{j}\right)$ are expressed as the form of rate. Therefore, $f(x)$ and $g(y)$ show no units in Equations 5 and 6. 


\section{Coordination degree analysis}

The coordination degree reflects how uniform the development of different components within a system is, and it can be described as

$$
\begin{gathered}
C=\left\{\frac{f(x) \times g(y)}{\left[\frac{f(x)+g(y)}{2}\right]^{2}}\right\}^{k} \\
T=\alpha f(x)+\beta g(y) \\
D=\sqrt{C \times T}
\end{gathered}
$$

In the above equations (Eqs. 7-9), $C$ represents the coordination degree, $k$ represents accommodation coefficient (let $k=2$ in this study), $T$ represents comprehensive evaluation index of economic system and water environmental system. $\alpha$ and $\beta$ are undetermined coefficients, in this study, let $\alpha=\beta=0.5$ as they are equally important. $D$ is the coordinated development coefficient (Ozturk and Al-Mulali, 2015; Ozturk and Uddin, 2012).

\section{Structural equation model}

\section{Model principle}

Structural equation model is a multivariate statistical analysis method to validate the relationship between independent and dependent variables. Apart from reflecting the relationship among latent variables, it can also explore the relationship between latent variables and observed variables. Latent variables are those that can not be measured accurately and directly, they can be measured with some observed variables indirectly. The structural equation model consists of the measurement section and the structural section.

The measurement model (Eqs. 10 and 11) describes the relationship between latent variables and observed variables, while the structural model (Eq. 12) reflects the relationship among latent variables.

$$
\begin{gathered}
x=\Lambda_{x} \xi+\delta \\
y=\Lambda_{y} \eta+\varepsilon \\
\eta=B \eta+\Gamma \xi+\zeta
\end{gathered}
$$

where $x$ represents exogenous variables observed vector; $\xi$ represents exogenous latent variable vector; $\Lambda_{x}$ represents the relationship between exogenous variables and exogenous latent variables, and $\Lambda_{x}$ is the factor loading matrix of exogenous variables observed in the exogenous latent variables; $\delta$ represents the residuals vector exogenous observable variables; $y$ is the endogenous observable variable to the amount; $\eta$ is the endogenous latent variable vector; $\Lambda_{y}$ represents relationship between observation 
variables and latent variables; $\varepsilon$ is the residuals vector of endogenous variables observed; $B$ and $\Gamma$ are the path coefficient relation matrix, $B$ is endogenous latent variables, $\Gamma$ effects of exogenous latent variables for the endogenous latent variable values; $\zeta$ is the error term of structure equation (Rahman et al., 2016).

\section{Model assumptions}

In this study, the Structural Equation Model of Beijing Economic \& Water Environment System was built based on the following assumptions:

H1: The water supply subsystem has an impact on the population subsystem; $\mathrm{H} 2$ : The water supply subsystem has an impact on the economic development subsystem; H3: The water supply subsystem has an impact on the water environmental carrying capacity subsystem; H4: The population subsystem has an impact on the economic development subsystem; H5: The population subsystem has an impact on the water environmental carrying capacity subsystem; H6: The economic development subsystem has an impact on the water environmental carrying capacity subsystem ( $\mathrm{Su}$ et al., 200).

Based on the above assumptions, the initial conceptual model of economic \& water environmental system in Beijing is shown in Figure 3.

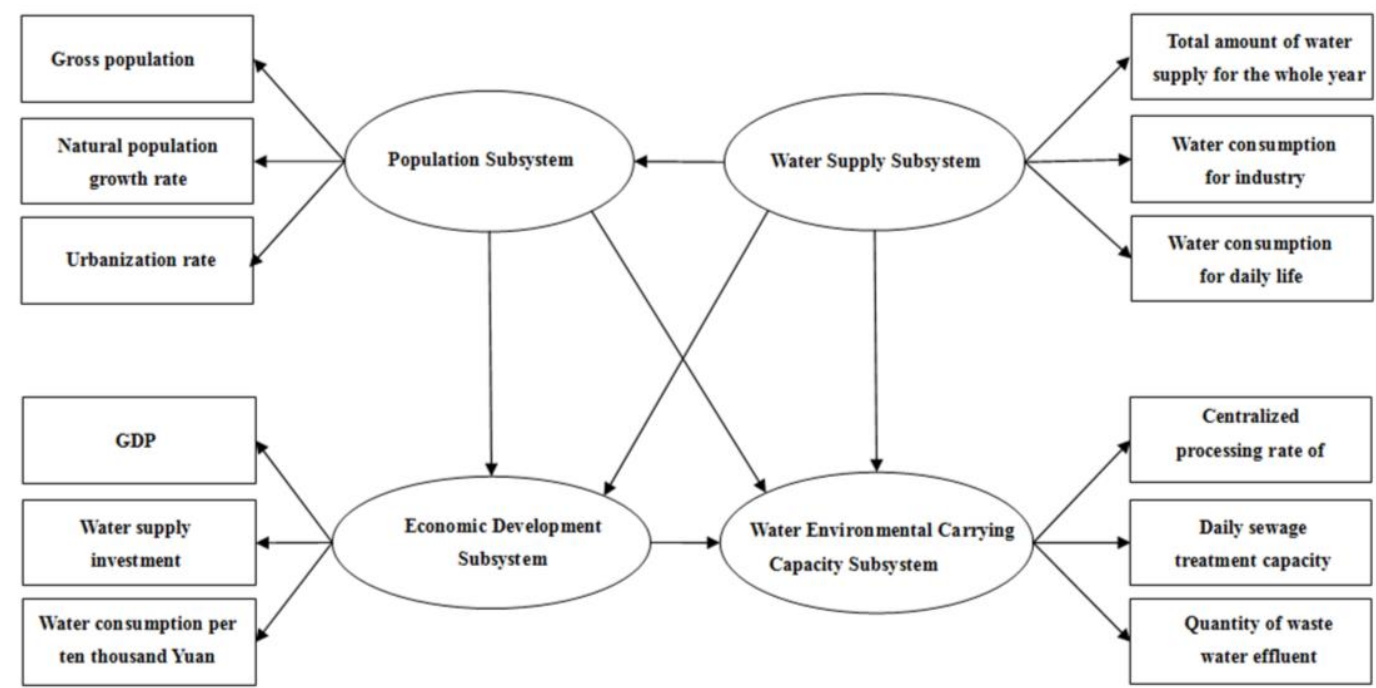

Figure 3. The initial conceptual model of economic \& water environmental system in Beijing

\section{Model test}

(1) Reliability test

Reliability refers to the degree of consistency (stability) of measurement results. The currently used method is Cronbach's $\alpha$ reliability coefficient. Cronbach's $\alpha$ reliability coefficient is currently the most widely used method. Cronbach proposed this new reliability test method in 1951. This method compares the results of any item in the measurement tool with all other items and makes the internal consistency of the scale more cautious. The equation is as follows (Eq. 13):

$$
\alpha=\frac{k}{k-1}\left(1-\frac{\sum S_{i}^{2}}{S_{T}^{2}}\right)
$$


where $k$ is the total number of items in the scale, $S_{i}^{2}$ is the variance within the score of the $i$-th question, and $S^{3} T$ is the variance of the total score of all items. It can be seen from Equation 13 that the $\alpha$ coefficient evaluates the consistency between the scores of each item in the scale and belongs to the internal consistency coefficient. In general, the reliability coefficient of the total scale is preferably above 0.8 , acceptable between 0.7 and 0.8 ; the reliability coefficient of the subscale is preferably above 0.7, and 0.6 0.7 is acceptable. If the Cronbach's $\alpha$ coefficient is below 0.6, the Structural Equation Model (SEM) should be corrected (Baek and Kim, 2013; Xiao et al., 2014).

(2) Goodness of fit evaluation

The goodness of fit of the model refers to the degree of consistency between the theoretical hypothesis model and the observed data. According to the principle of parameter estimation of the structural equation model, it refers to the covariance matrix $\sum(\theta)$ and the sample covariance matrix $S$ generated in the estimation. Proximity, a viable model should make the difference between $S$ and $\sum(\theta)$ as small as possible.

In general, the commonly used fitting evaluation index has the following three categories: (1) Absolute Indices; (2) Relative/Incremental Indices; (3) Parsimony Indices (Chai et al., 2011; Costanza et al., 2013). The classification results of fitting evaluation index are shown in Table 2.

Table 2. The classification results of fitting evaluation index of structural equation model

\begin{tabular}{|c|c|c|c|c|}
\hline Index name & $\begin{array}{c}\text { Statistic } \\
\text { of test }\end{array}$ & $\begin{array}{l}\text { Explanation of } \\
\text { terms }\end{array}$ & Form of expression & $\begin{array}{l}\text { Standard or } \\
\text { critical value of fit }\end{array}$ \\
\hline \multirow{4}{*}{$\begin{array}{l}\text { Absolute fit } \\
\text { indices }\end{array}$} & $\chi^{2} / \mathrm{df}$ & Likelihood - ratio $\chi^{2}$ & $-2 \ln \left(\frac{L_{1}}{L_{0}}\right)=-2\left(\ln L_{1}-\ln L_{0}\right)=(N-1) F_{M L} \sim \chi^{2}\left(\frac{1}{2} q(q+1)-k\right)$ & $<3$ \\
\hline & GFI & Goodness of index & $G F I_{G L S}=1-\frac{\operatorname{tr}\left|\left[1-\hat{\Sigma}(\theta) S^{-1}\right]^{2}\right|}{q}$ & $>0.9$ \\
\hline & RMR & & $R M R=\sqrt{\frac{2 \sum \sum\left(s_{i j}-\hat{\sigma}_{i j}\right)}{(p+q)(p+q+1)}}$ & $<0.05$ \\
\hline & RMSEA & $\begin{array}{l}\text { Root mean square } \\
\text { error of } \\
\text { approximation }\end{array}$ & $F_{0}=\max \left\{\frac{\hat{F}-d f}{N-1}, 0\right\}$ & $<0.08$ \\
\hline \multirow{3}{*}{$\begin{array}{l}\text { Relative fit } \\
\text { indices }\end{array}$} & NFI & Normed fit index & $N F I=\frac{F_{b}-F_{m}}{F_{b}}=\frac{\chi_{b}^{2}-\chi_{m}^{2}}{\chi_{b}^{2}}$ & $0.9<\mathrm{NFI}<1$ \\
\hline & TLI & Tacker-Lewis index & $T L I=N N F I=\frac{\frac{\chi_{b}^{2}}{d f_{b}}-\frac{\chi_{m}^{2}}{d f_{m}}}{\frac{\chi_{b}^{2}}{d f_{b}}-1}$ & $0.9<\mathrm{TLI}<1$ \\
\hline & CFI & Comparative fit index & $C F I=1-\frac{\tau_{m}}{\tau_{b}}$ & $0.9<\mathrm{CFI}<1$ \\
\hline \multirow{2}{*}{$\begin{array}{l}\text { Parsimonious } \\
\text { fit indices }\end{array}$} & AIC & $\begin{array}{l}\text { Akaike information } \\
\text { criterion }\end{array}$ & $A I C=\chi^{2}+2 k$ & $\begin{array}{l}\text { The smaller, the } \\
\text { better }\end{array}$ \\
\hline & CAIC & $\begin{array}{l}\text { Continuous Akaike } \\
\text { information criterion }\end{array}$ & $C A I C=\chi^{2}+(\ln N) k$ & $\begin{array}{l}\text { The smaller, the } \\
\text { better }\end{array}$ \\
\hline
\end{tabular}




\section{Results}

\section{The results of the coordinate coordination model}

Based on the coupling coordination degree model built above, we input the related data from 1997 to 2013 into Equations 1-9 mentioned above to calculate the coupling degree, and the results are shown in Table 3.

Table 3. The results of the coordinated development of economic and water environmental systems in Beijing (1997-2013)

\begin{tabular}{c|c|c|c}
\hline Year & $\begin{array}{c}\text { The comprehensive indexes } \\
\text { of economic system } \boldsymbol{f}(\boldsymbol{x})\end{array}$ & $\begin{array}{c}\text { The comprehensive indexes of } \\
\text { water environmental system } \boldsymbol{g}(\boldsymbol{y})\end{array}$ & $\begin{array}{c}\text { Coordinated development } \\
\text { coefficient } \boldsymbol{D}\end{array}$ \\
\hline 1997 & 0.1177 & 0.2268 & 0.0072 \\
1998 & 0.1196 & 0.2185 & 0.0071 \\
1999 & 0.1625 & 0.2331 & 0.0120 \\
2000 & 0.1966 & 0.3357 & 0.0239 \\
2001 & 0.1861 & 0.4104 & 0.0277 \\
2002 & 0.2379 & 0.5014 & 0.0504 \\
2003 & 0.2168 & 0.5069 & 0.0444 \\
2004 & 0.3532 & 0.5891 & 0.1102 \\
2005 & 0.3797 & 0.6968 & 0.1501 \\
2006 & 0.4336 & 0.7053 & 0.1859 \\
2007 & 0.6539 & 0.7400 & 0.3649 \\
2008 & 0.6603 & 0.7370 & 0.3685 \\
2009 & 0.7057 & 0.7607 & 0.4231 \\
2010 & 0.6723 & 0.7610 & 0.3937 \\
2011 & 0.8801 & 0.7607 & 0.5894 \\
2012 & 0.9094 & 0.7684 & 0.6266 \\
2013 & 0.9829 & 0.7657 & 0.7011 \\
\hline
\end{tabular}

According to the results of data processing in Table 3, the trend of the coordinated development coefficient of economic and water environmental systems in Beijing is plotted (Fig. 4).

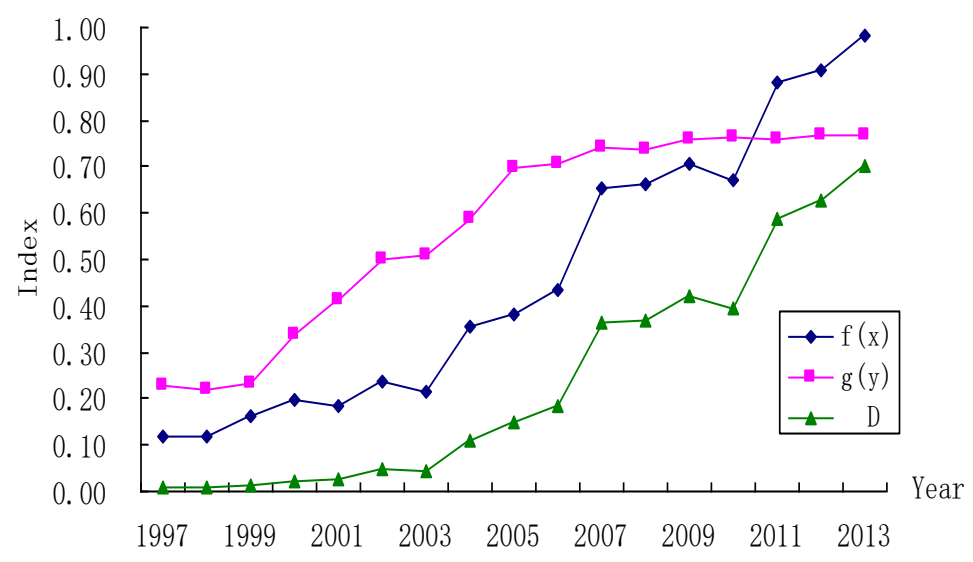

Figure 4. The coordinated development coefficient of the economic system and the water environmental system of Beijing (1997-2013) 
It can be seen from Figure 4 that during 1997 to 2013, the economic system composite index increased from 0.1177 in 1997 to the highest value of 0.9829 in 2013 . The lowest value of water environment index appeared in 1998, the index value was 0.2185 , while the highest value was 0.7684 appeared in 2012. In general, the relationship between Beijing's socio-economic and its protection of the coordinated development of the water environment was good. The degree of coordination between them showed an overall upward trend, and the degree of coupling increased continuously. The coefficient of coordinated development of the economic system and the water environmental system of Beijing increased from the lowest value of 0.0071 in 1998 to the highest value of 0.7011 in 2013.

\section{The results of the structural equation model}

\section{Assumptions test}

In this paper, Cronbach's $\alpha$ was used to measure the intrinsic reliability of the data, when $\alpha>0.8$, it shows that the data has good reliability (Baveye et al., 2013). The results of $\alpha$ were obtained by Statistical Product and Service Solutions (SPSS) software with the data of 12 indicators from 1997 to 2013 of Beijing (Table 4).

Table 4. The results of Cronbach's $\alpha$ of structural equation model in Beijing (1997-2013)

\begin{tabular}{c|c|c|c}
\hline Latent variable & $\begin{array}{c}\text { The number of } \\
\text { variables }\end{array}$ & Cronbach's $\alpha$ & $\begin{array}{c}\text { Reliability } \\
\text { judgment }\end{array}$ \\
\hline Population subsystem & 3 & 0.956 & Yes \\
Economic development subsystem & 3 & 0.933 & Yes \\
Water supply subsystem & 3 & 0.851 & Yes \\
Water environment carrying capacity subsystem & 3 & 0.982 & Yes \\
\hline
\end{tabular}

\section{Calculation of structural equation model}

The 12 indicators data (from 1997 to 2013 of Beijing) were put into the Structural Equation Model (SEM)l, and the Maximum Likelihood Estimate method were used to estimate the model parameters by AMOS 7.0 software (Table 5). On this basis, the paths of the model were corrected according to M.I prompt value and the actual situation. Finally, the results of the mode were shown by Figure 5.

Table 5. The summary table of overall model fit test in confirmatory factor analysis of structural equation model in Beijing (1997-2013)

\begin{tabular}{c|c|c|c|c}
\hline Index name & Statistic of test & $\begin{array}{c}\text { Standard or critical } \\
\text { value of fit }\end{array}$ & Test result & $\begin{array}{c}\text { Model fit } \\
\text { judgment }\end{array}$ \\
\hline \multirow{4}{*}{ Absolute fit indices } & $\chi^{2} / \mathrm{df}$ & $<3$ & 2.01 & Yes \\
& GFI & $>0.9$ & 0.906 & Yes \\
& RMR & $<0.05$ & 0.044 & Yes \\
& RMSEA & $<0.08$ & 0.076 & Yes \\
\hline \multirow{3}{*}{ Relative fit indices } & NFI & $0.9<$ NFI $<1$ & 0.962 & Yes \\
& TLI & $0.9<$ TLI $<1$ & 0.954 & Yes \\
& CFI & $0.9<$ CFI $<1$ & 0.949 & Yes \\
\hline \multirow{2}{*}{ Parsimonious fit indices } & AIC & The smaller, the better & 292.17 & Yes \\
& CAIC & The smaller, the better & 245.33 & Yes \\
\hline
\end{tabular}




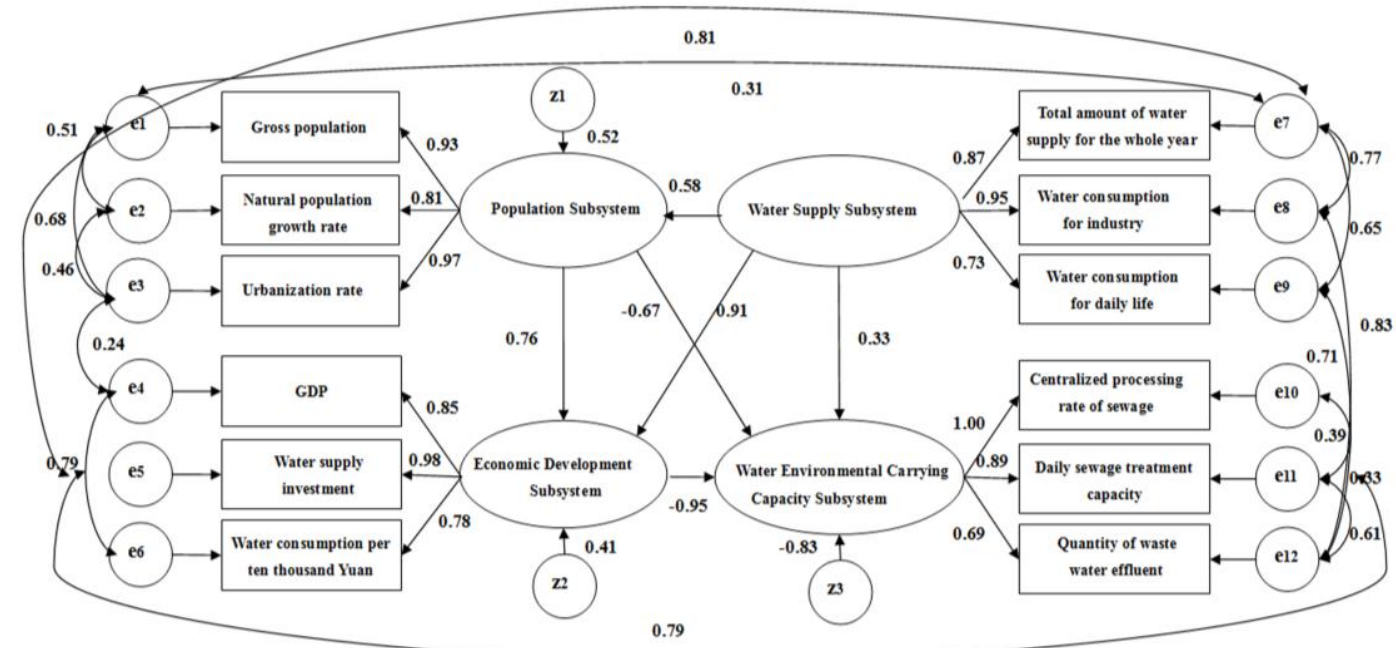

Figure 5. The standardized coefficient model of economic \& water environmental system in Beijing

According to the results shown in Table 5, it can be found that the basic fitness index of the structural equation model, such as GFI, NFI, AIC all meet the test standard. The results also show that the modified model supports the initial hypothesis, and it has a good fitting effect (Spash, 2011).

The population subsystem has a strong positive influence on the economic development subsystem, and its path coefficient is 0.76 . It shows that when the amount of population increases 1 unit, the corresponding amount of economic development will increase 0.76 units. The population subsystem has a strong negative impact on the water environmental carrying capacity subsystem, and its path coefficient is -0.62 . It shows that when the amount of population increases 1 unit, the corresponding amount of water environmental carrying capacity will decrease -0.62 units. The water supply subsystem has a significant positive effect on the economic development subsystem, and its path coefficient is 0.91. Thus, when the value of water supply increases 1 unit, the corresponding amount of economic development will increase 0.91 units. The economic development subsystem has a significant negative effect on the water environmental carrying capacity subsystem, and its path coefficient is -0.98 . Thus, when the amount of economic development increases 1 unit, the corresponding amount of water environmental carrying capacity will decrease 0.98 units. The water supply subsystem has a weak positive influence on the population subsystem, and its path coefficient is 0.48. It shows that when the amount of water supply increases 1 unit, the corresponding amount of economic development will increase 0.48 units. The water supply subsystem has a weak positive influence on the water environmental carrying capacity subsystem, and its path coefficient is 0.32 . It shows that when the amount of water supply increases 1 unit, the corresponding amount of water environmental carrying capacity will increase 0.32 units.

\section{Discussion}

In the existing research on system coupling theory, the research involving economic system and environmental system often pays attention to the coupling relationship 
between macroeconomics and the whole environment. Representative scholars of this research area include Jiang, H., He, J., Wu, Y. and Zhang, Z. Their research rarely focuses on a refinement of the water environment (Jiang and He, 2010; Panayotou, 1995). In this article, we try to focus on the water environment system and highlighted the characteristics of the water environment system. In terms of specific research content: most scholars have not researched the coupling system from multiple perspectives. For example, Liu, Y., Li, R., Song, X. only measure the coupling state of the system, and then evaluate the coupling effect of the system. There is a lack of indepth study of the micro-coupling paths (Wu et al., 1996; Dinda, 2004). A few scholars' research involves micro-coupling paths by mechanism model only (Liu et al., 2005; Zuo and Chen, 2001). And the lack of mathematical analysis of specific coupling paths is a common shortcoming in their researches. In contrast, this article explores the system coupling law from the two perspectives of macroscopic state and microscopic paths. The detailed discussions are as follows:

\section{Discussion of coupling state}

In this paper, we try to divide the coupling state between the economic system and water environmental system in Beijing from 1997 to 2013 into 5 different stages. According to the classification criteria, the coordinated development coefficient of the economic system and water environmental system in Beijing from 1997 to 2013 is divided into stages as shown in Table 6 (Chen and $\mathrm{Xu}, 2014$ ).

Table 6. The classification standard of coordinated development coefficient

\begin{tabular}{c|c}
\hline Coordinated development coefficient (D) & Standard \\
\hline $0 \leq \mathrm{D} \leq 0.1$ & Serious uncoordinated stage \\
$0.1<\mathrm{D} \leq 0.3$ & Uncoordinated stage \\
$0.3<\mathrm{D} \leq 0.5$ & Basic coordinated stage \\
$0.5<\mathrm{D} \leq 0.7$ & Good coordinated stage \\
$0.7<\mathrm{D} \leq 1$ & High quality coordinated stage \\
\hline
\end{tabular}

(1) Serious uncoordinated stage (1997-2003). In the past, the development of water conservancy in Beijing has been neglected due to the high attention paid to economic growth and urbanization by the State and the Beijing Municipal Government. The city's weak sewage treatment caused serious water pollution. Therefore, the coordinated development coefficient of the economic system and the water environmental system in Beijing was so low in a very long period of time,. this period was the serious uncoordinated stage.

(2) Uncoordinated stage (2004-2006). In 2004, with the success of China's accession to the WTO and the accelerated adjustment of the national economic structure, Beijing's economic development also ushered in a new opportunity to optimize the economic structure. It eliminated high water consumption and high pollution industries. At the same time, Beijing increased the investment in water pollution control, its water pollution treatment capacity also increased to a certain extent. However, due to the lack of investment in water resources, sewage discharge still increased. The coordinated development coefficient of the economic system and the water environmental system in Beijing was in the uncoordinated stage. 
(3) Basic coordinated stage (2007-2010). After 2007, with the Beijing Olympic Games approaching, the environmental protection of Beijing was imminent. The investment in the field of water environmental protection increased rapidly, and the adjustment of the industrial structure was also further accelerated. Beijing has introduced a large number of advanced sewage treatment technology, thus the daily sewage treatment capacity and sewage treatment rate have been greatly improved. During this period, the coordinated development coefficient of the economic system and the water environmental system in Beijing was in the basic coordinated stage.

(4) Good coordinated stage (2011-2012). From 2011 to 2012, the construction of energy-saving economy in Beijing was increasingly perfect. During this period, Beijing's per capita GDP continued to increase, and investment in water supply increased a lot, while the industrial water consumption and domestic water consumption remained basically unchanged. The degree of coordination between the Beijing economic system and the water environmental system was further improved, and it was in a good coordination stage.

(5) High quality coordinated stage (2013). In 2013, the scientific concept of development has been subjected to more attention by all walks of life. Beijing's economic level of urbanization, per capita GDP and many other indicators reached the maximum in recent years. At the same time, Beijing's water pollution treatment capacity continued to improve, industrial water, domestic water demand was stable. The coordination degree between the Beijing economic system and the water environmental system reached the optimal state and was in the stage of high-quality coordination.

\section{Discussion of coupling paths}

\section{(1) Coupling paths of population subsystem}

The population subsystem has a positive impact on the economic development subsystem, and the population subsystem has a negative impact on the water environmental carrying subsystem. The reason is that, the Beijing's economic \& water environmental system is a Pressure-State-Response (P-S-R) system. In this whole system, the population subsystem belongs to the "Pressure Part" (P), the economic development subsystem belongs to the "State Part" (S), and the water environmental carrying subsystem belongs to the "Response Part" (R). The "Pressure Part" (P) promotes the "State Part" (S), which is positively affected, while the "Response Part" (R) has a feedback effect on the "Pressure Part" (P), showing a negative influence. Population growth means the growth of labor and the expansion of the market, thus providing the driving force for economic development. In contrast, the domestic sewage generated by population growth has no serious burden on the water environment. That is, the contribution of population growth to economic development is greater than the burden on the water environment. Therefore, the absolute value of the path coefficient is $0.76>0.67$.

\section{(2) Coupling paths of economic development subsystem}

The economic development subsystem has a negative impact on the water environment carrying subsystem. The reason is that, the Beijing's economic \& water environmental system is a Pressure-State-Response (P-S-R) system. The economic development subsystem belongs to the "State Part"(S), while the water environmental carrying subsystem belongs to the "Response Part"(R). The "Response Part"(R) has a 
feedback effect on the "State Part"(S), showing a negative influence. Thus, if the shortage of water supply appears, it will hinder economic development.

\section{(3) Coupling paths of water supply subsystem}

The water supply subsystem has a positive impact on the population subsystem, and the water supply subsystem has a positive impact on the economic development subsystem. Meanwhile, the water supply subsystem has a positive impact on the water environment carrying subsystem. The same reason is that, the Beijing's economic \& water environmental system is a Pressure-State-Response (P-S-R) system. In this whole system, the population subsystem belongs to the "Pressure Part" $(\mathrm{P})$, the economic development subsystem and water supply subsystem belong to the "State Part"(S), and the water environmental carrying subsystem belongs to the "Response Part"(R). The "State Part"'(S) has a feedback effect on the "Pressure Part"(P), showing a negative influence. The "Pressure Part"( $(\mathrm{P})$ promotes the "State Part"( $\mathrm{S})$, which is positively affected. And the "State Part"(S) also promotes the "State Part"(S), which is positively affected. Therefore, all three coupled paths show positive effects. Moreover, the water resources of the water supply subsystem can provide the necessary resource elements for economic development firstly (Barrieu and Fehr, 2014; Wesseh and Lin, 2013). Obviously, the abundant water resources and the developed economy work together to create a livable environment, on the basis of which to promote population growth. It cannot be ignored that abundant water supply can also reduce the pollution of the water environment. Therefore, the contribution of water supply to economic development is greater than the promotion of population growth, and the improvement of water supply to water environment pollution is less than the promotion of population growth. Thus, the result of the absolute value of the path coefficient shows $0.91>0.58>0.33$.

\section{(4) Coupling paths of water environmental carrying subsystem}

The coupling paths of water environmental carrying subsystem are embodied in the above 3 coupling paths. Thus, the coupling path of water environmental carrying subsystem will not be discussed again in this paragraph.

\section{Conclusions}

(1) From the macroscopic point of view, the economic system and water environmental system couple with each other and have complex interactions. With the optimizing of economic structure and advancing in technologies, the coupling degree would increase between the two systems.

At the early development stage of Beijing, more emphasis was placed on the increase in economy, leading to unbalanced development with heavy pollution and higher energy consumption, and causing great pollution to the ecology, especially to the water environment. In this stage, the economic system and the water environment system had lower coupling degree. With the optimization of the economic structure and the development of energy-saving economy, development in a scientific and sustainable way is more and more valued, and the coupling degree is getting higher while the development is getting more balanced.

(2) From the microscopic point of view, there are complex coupling paths among the population subsystem, economic development subsystem, water supply system and 
water environmental carrying capacity subsystem. Besides, these four subsystems influence each other.

The water supply subsystem has a certain degree of promotion effect to the other three subsystems, thus the city's development can be promoted effectively through improving the level of water supply. Similarly, the population subsystem plays a critical role in promoting the economic development subsystem. Thus it can be concluded that accelerating urbanization is an effective way to promote economic development. On the contrary, the water environmental carrying capacity subsystem is strongly obstructed by the economic development subsystem and the population subsystem. Therefore, the development of the city should be in accordance with its corresponding water environment carrying capacity.

Acknowledgements. This research is supported by (1) National Natural Science Foundation of China (No: 51279058 \& No: 41471456); (2) The Major Program of University Natural Science Foundation of Jiangsu Province (No: 14KJA170006); (3) The Joined PhD student program funded by China Scholarship Council (No: 201506710057).

\section{REFERENCES}

[1] Ahmed, A., Uddin, G. S., Sohag, K. (2016): Biomass energy, technological progress and the environmental Kuznets curve: evidence from selected European countries. - Biomass Bioenergy 90: 202-208.

[2] Aldy, J. E. (2005): An environmental Kuznets curve analysis of US state-level carbon dioxide emissions. - J. Environ Dev. 14: 48-72.

[3] Apergis, N., Ozturk, I. (2015): Testing environmental Kuznets hypothesis in asiancountries. - Ecol. Indic. 52: 16-22.

[4] Arouri, M. E. H., Ben Youssef, A., M'henni, H., Rault, C. (2012): Empirical analysis of the EKC hypothesis for sulfur dioxide emissions in selected Middle East and North African countries. - J Energy Dev. 37: 207-26.

[5] Baek, J., Kim, H. S. (2013): Is economic growth good or bad for the environment? Empirical evidence from Korea. - Energy Econ. 36: 744-749.

[6] Barrieu P, Fehr, M. (2014) Market-consistent modeling for cap-and-trade schemes and application to option pricing. - Operations Res. 62: 234-49.

[7] Baveye, P. C., Baveye, J., Gowdy, J. (2013): Monetary valuation of ecosystem services: it matters to get the timeline right. - Ecol. Econ. 95: 231-235.

[8] Ben Jebli, M., Youssef, S. B., Ozturk, I. (2016): Testing environmental Kuznets curve hypothesis: the role of renewable and non-renewable energy consumption and trade in OECD countries. - Ecol. Indic. 60: 824-831.

[9] Chai, S, Yan, J, Yang, J. (2011): Coupling and coordination degree of economic growth and environmental pollution levels in Shanxi Province. - Journal of Arid Land Resources and Environment 25(1): 130-135.

[10] Chen, M., Xu, C. (2013): Study on water pollution causes and prevention of Jiangsu rural areas. - Journal of Chemical and Pharmaceutical Research 5(12): 532-536.

[11] Chen, M., Xu, C. (2014) Study of urban economic and environmental system coordinated development measure - take Nantong City as the example. - International Journal of Applied Environmental Sciences 9(4): 1603-1613.

[12] Corinne, G. (2014): Beyond environmental and ecological economics: Proposal for an economic sociology of the environment. - Ecol. Econ. 105: 240-254. 
[13] Coscieme, L., Pulselli, F. M., Niccolucci, V., Patrizi, N., Sutton, P. C. (2016): Accounting for "land-grabbing" from a biocapacity viewpoint. - Sci. Total Environ. 539: 551-559.

[14] Costanza, R., Alperovitz, G., Daly, H., Farley, J., Franco, C., Jackson, T., Kubiszewski, I., Schor, J., Victor, P. (2013): Building a Sustainable and Desirable Economy-in-Societyin-Nature. - ANU E Press, Canberra, Australia.

[15] Dinda, S. (2004): Environmental Kuznets curve hypothesis: A survey. - Ecological Economics 49(4): 431-455.

[16] Douai, A., Mearman, A., Negru, I. (2012): Prospects for a heterodox economics of the environment and sustainability. - Camb. J. Econ. 36: 1019-1032.

[17] Flores, C. A,. Flores-Lagunes, A., Kapetanakis, D. (2014): Lessons from quantile panel estimation of the environmental Kuznets curve. - Econom Rev. 33: 815-53.

[18] Jiang, H., He, J. (2010): The dynamic coupling of coordinated development between regional economic and ecological environment systems based on Jiangsu province. - Soft Sciences 24(3): 63-68.

[19] Kanjilal, K., Ghosh, S. (2013): Environmental Kuznet's curve for India: evidence from tests for cointegration with unknown structural breaks. - Energy Policy 56: 509-515.

[20] Lin, B., Moubarak, M., Ouyang, X. (2014): Carbon dioxide emissions and growth of the manufacturing sector: evidence for China. - Energy 76: 830-837.

[21] Liu, Y, Li, R, Song, X. (2005) Grey associative analysis of regional urbanization and ecoenvironment coupling in China. - Acta Geographica Sinica 60(2): 237-247.

[22] Ozturk, I., Al-Mulali, U. (2015): Investigating the validity of the environmental Kuznets curve hypothesis in Cambodia. - Ecol. Indic. 57: 324-330.

[23] Ozturk, I., Uddin, G. S. (2012): Causality among carbon emissions, energy consumption and growth in India. - Econ. Res. 25(3): 752-775.

[24] Panayotou, T. (1995): Environment Degradation at Different Stages of Economic Development Livelihoods in the Third World. - Macmillan Press, London.

[25] Rahman, M. S., Noman, A. H. M., Shahari, F., Aslam, M., Gee, C. S., Isa, C. R., Pervin, S. (2016): Efficient energy consumption in industrial sectors and its effect on environment: a comparative analysis between G8 and Southeast Asian emerging economies. - Energy 97: 82-89.

[26] Spash, C. L. (2011): Social ecological economics: understanding the past to see the future. - Am. J. Econ. Sociol. 70(2): 340-375.

[27] Stern, D. I. (2001) Is there an environmental Kuznets curve for sulfur? - Journal of Environmental Economics and Management 1(1): 162-178.

[28] Su, X., Wang, J., Guo, M., Jiang, Z., Li, H., Niu, Y. (2010): Coupling relationship of agricultural eco-economic system in Wuqi County based on structural equation model. Chinese Journal of Applied Ecology 21(4): 937-944.

[29] Van der Ploeg, R., Withagen, C. (2013): Green growth, green paradox and the global economic crisis. - Environ. Innov. Soc. Transit. 6: 116-119.

[30] Wesseh, P. K. Jr., Lin, B. (2013) Owusu-Appiah, M. Delving into Liberia's energy economy: technical change, inter-factor and inter-fuel substitution. - Renew. Sustain. Energy Rev. 24: 122-30.

[31] Wu, Y., Zhang, Z, Lang, D. (1996): The forecasting model of environment-economy coordinated degree and its application. - Journal of Nanjing University: Natural Sciences 32(3): 466-472.

[32] Xia, Z., Wang, J., Yao, W., Lu, M. (2012): Coupling relationship between agricultural industry and resources in the loess hilly region on the background of conservation of water and soil-Based on the perspective of farmers-behavior. - Chinese Journal of EcoAgriculture 20(3): 369-377.

[33] Xiao, X., Xie, D., Ni, J. (2014): Coupling state of agricultural eco-economic system under emission mitigation and sink enhancement of non-point source pollution - A case 


$$
-632-
$$

study of Zhong County in the Three Gorges Reservoir Region. - Chinese Journal of EcoAgriculture 22(1): 111-119.

[34] Zuo, Q, Chen, X. (2001) Dynamic model of coupling system for social-economy and ecoenvironment. - Shanghai Environmental Sciences 20(12): 592-594. 